Supporting information

\title{
An Outright Green Synthesis of Fluorescent Carbon Dots from Eutrophic Algal Blooms for In Vitro Imaging
}

Vadivel Ramanan, Thiyagarajan Senthil Kumar, Raji Kaviyarasan, Ragupathy Suresh, Sekar Rajkumar, Perumal

$$
\text { Ramamurthy* }
$$

Table of contents of supporting information

1. Table S1. Optimization of phosphoric acid concentration for the synthesis of CDs

2. Table S2. Optimization of reaction conditions for the synthesis of CDs

3. Figure S1. Images of CDs

4. Zeta potential report

5. Figure S2. Apparent zeta potential distribution

6. Fluorescent quantum yield calculations

7. Figure S3. Slope method for QY calculation

8. Table S3. Slope method for QY calculation (Graphical)

9. Table S4. Calculated QY

10. Figure S4. Normalized emission spectra at various excitation wavelengths

11. Figure S5. Excitation spectra at various emission wavelengths

12. Figure S6. Fluorescence lifetime decay at various emission wavelengths

13. Table S5. Fitted parameters of fluorescence lifetime decay 
Table S1. Optimization of phosphoric acid concentration for the synthesis of CDs

\begin{tabular}{|c|c|c|c|c|}
\hline S. No. & \multicolumn{2}{|c|}{ Starting material ratio } & $\begin{array}{c}\text { QY relative to } \\
\text { Quinine } \\
\text { Sulphate (\%) }\end{array}$ & $\begin{array}{c}\text { Peak } \\
\text { position (360 } \\
\text { nm } \\
\text { excitation) }\end{array}$ \\
\hline 1 & Algae, $1 \mathrm{~g}$ & $\mathrm{H}_{3} \mathrm{PO}_{4}, 20 \%$ & 5.3 & 435 \\
\hline 2 & Algae, $1 \mathrm{~g}$ & $\mathrm{H}_{3} \mathrm{PO}_{4}, 30 \%$ & 8.1 & 433 \\
\hline 3 & Algae, $1 \mathrm{~g}$ & $\mathrm{H}_{3} \mathrm{PO}_{4}, 40 \%$ & 13.0 & 438 \\
\hline 4 & Algae , $1 \mathrm{~g}$ & $\mathrm{H}_{3} \mathrm{PO}_{4}, 50 \%$ & 13.2 & 440 \\
\hline 5 & Algae , $1 \mathrm{~g}$ & $\mathrm{H}_{3} \mathrm{PO}_{4}, 0 \%$ & --- & -- \\
\hline
\end{tabular}

\section{Data Notes:}

1. The MWI output power is maintained at $600 \mathrm{~W}$ for $5 \mathrm{~min}$. for all the reaction conditions.

2. The weight of algae kept constant while the percentage of phosphoric acid is altered.

3. The fluorescence QY is better when using $40 \%$ phosphoric acid.

4. When the concentration of phosphoric acid is raised above $40 \%$, there is no appreciable change in the fluorescence quantum yield. Rather it creates difficulty in removing the excess phosphoric acid. Precipitation of trisodium phosphate and dialysis required more time. Therefore the concentration of phosphoric acid is fixed at $40 \%$.

5. In the absence of phosphoric acid, the carbon dots do not formed. So it is clear that phosphoric acid is very important to facilitate the formation of CDs most probably by oxidative pyrolysis. Consequently, the formed CDs are rich in oxygen content (41\%) as confirmed by XPS elemental composition analysis. 
Table S2. Optimization of reaction condition for the synthesis of CDs.

\begin{tabular}{|c|c|c|c|c|}
\hline \multirow{2}{*}{ S. No. } & \multicolumn{2}{|c|}{$\begin{array}{c}\text { CDs from different reaction } \\
\text { conditions }\end{array}$} & \multirow{2}{*}{$\begin{array}{c}\text { Weight of } \\
\text { obtained CDs } \\
\text { (mg) }\end{array}$} & \multirow{2}{*}{$\begin{array}{c}\text { QY relative to } \\
\text { Quinine } \\
\text { Sulphate }(\%)\end{array}$} \\
\hline & $\begin{array}{l}\text { MW Power } \\
\text { (W) }\end{array}$ & $\begin{array}{l}\text { Irradiation } \\
\text { time }\end{array}$ & & \\
\hline 1 & 400 & $8 \mathrm{~min}$. & --- & --- \\
\hline 2 & 600 & $4 \mathrm{~min}$. & 32 & 9.7 \\
\hline 3 & 600 & $5 \mathrm{~min}$. & 66 & 12.6 \\
\hline 4 & 600 & $\begin{array}{l}5 \mathrm{~min} .50 \\
\mathrm{sec} .\end{array}$ & 81 & 14.0 \\
\hline 5 & 600 & $7 \mathrm{~min}$. & 110 & 11.3 \\
\hline 6 & 800 & $2 \mathrm{~min}$. & --- & --- \\
\hline
\end{tabular}

\section{$\underline{\text { Data Notes: }}$}

1. The reagent ratio is kept constant i.e. $1 \mathrm{~g}$ algae and $40 \%$ Phosphoric acid are taken as the reactants.

2. At $400 \mathrm{~W}$ power, the $\mathrm{CDs}$ does not formed even at $8 \mathrm{~min}$. irradiation time.

3. At $800 \mathrm{~W}$ power, we have obtained a black mass due to charring of the precursor even at 2 min. irradiation time. The fluorescence is too small in such a way that the fluorescence 
quantum yield measurement is meaningless. The charring occurred very quickly at a point so that the reaction is uncontrollable.

4. The highest fluorescence quantum yield (about 13\%) is obtained when $1 \mathrm{~g}$ of precursor dispersed in 40\% Phosphoric acid and is irradiated for $5 \mathrm{~min}$. and $50 \mathrm{sec}$. at $600 \mathrm{~W}$.

5. The highest production yield (about $110 \mathrm{mg}$ ) is obtained for $1 \mathrm{~g}$ of algae in presence of $40 \%$ Phosphoric acid irradiated for $7 \mathrm{~min}$. at $600 \mathrm{~W}$. Hence, it is a scalable method for the commercial production of CDs.
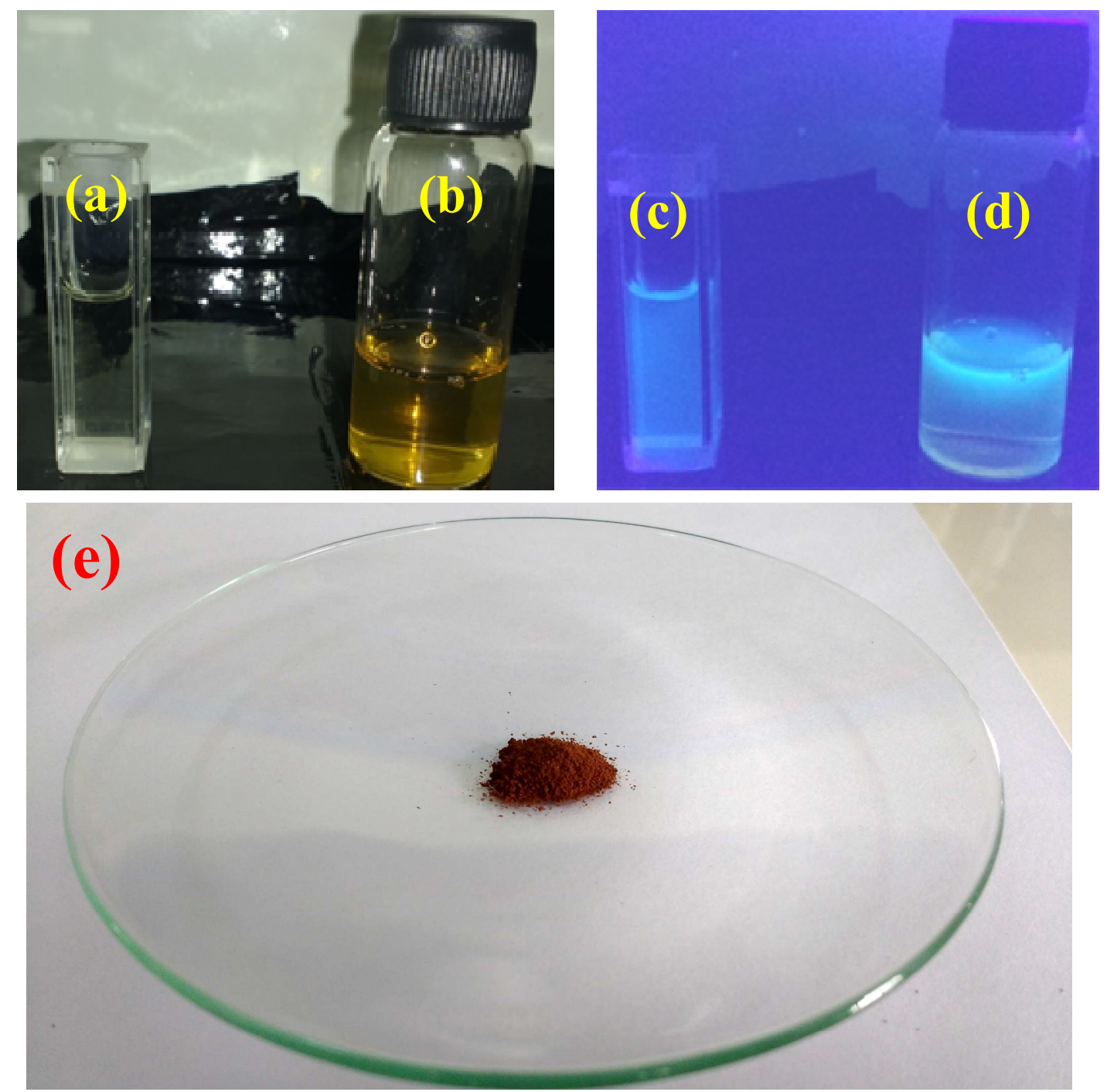
Figure S1. Images of CDs at day light illumination (a) diluted solution (b) as-prepared CDs, Images of CDs at $365 \mathrm{~nm}$ UV illumination (c) diluted solution (d) as-prepared CDs, (e) finely powdered CDs. 


\section{Zeta Potential Report}

v2.3

Malvern Instruments Ltd - $\oplus$ Copyright 2008

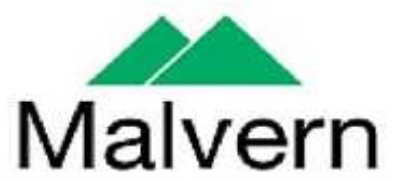

Sample Details

Sample Name: 2 ALG ZETA 1

SOP Name: mansettings.nano

General Notes:

File Name: UNIVERSITY OF MEDRAS.dts Record Number: 10

Dispersant Name: Water

Date and Time: Thursday, May 07, 2015 9:05:32 ...

Dispersant RI: 1.330

Viscosity (CP): 0.8872

Dispersant Dielectric Constant: 78.5

\section{System}

Temperature $\left({ }^{\circ} \mathrm{C}\right): 25.0$

Count Rate (kcps): 221.6

Cell Description: Zeta dip cell
Zeta Runs: 12

Measurement Position (mm): 4.50

Attenuator: 11

\section{Results}

Zeta Potential (mV): -22.3

Zeta Deviation $(\mathrm{mV}): 8.39$

Conductivity $(\mathrm{ms} / \mathrm{cm}): 0.556$

Result quality : Good

Mean $(\mathrm{mV}) \quad$ Area $(\%) \quad$ St Dev $(\mathrm{mV})$

$\begin{array}{llll}\text { Peak 1: } & -22.3 & 100.0 & 8.39 \\ \text { Peak 2: } & 0.00 & 0.0 & 0.00 \\ \text { Peak 3: } & 0.00 & 0.0 & 0.00\end{array}$

Zeta Potential Distribution

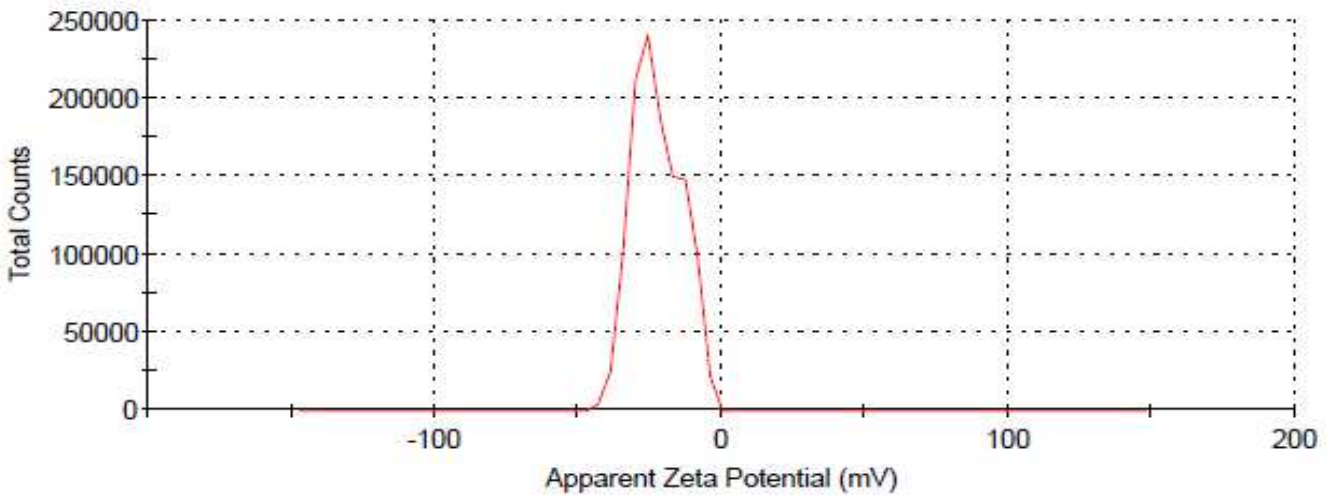

Record 10: 2 ALG ZETA 1

Figure S2. Apparent zeta potential distribution 


\section{Quantum yield calculations}

Quinine sulfate, QS $\left(0.1 \mathrm{~N} \mathrm{H}_{2} \mathrm{SO}_{4}\right.$ as solvent; Known QY $\left.=0.54\right)$ was chosen as standard. The QYs of CDs (in water) were calculated by two different methods. The average error was less than 5\% for these two kinds of methods. The QYs in Table S1 and S2 are based on the first method.

1. The QY was determined by reference point method.

$$
Q Y_{\text {sam }}=Q Y_{\text {ref }}\left(I_{\text {sam }} / \mathbf{I}_{\text {ref }}\right)\left(A_{\text {ref }} / \mathbf{A}_{\text {sam }}\right)\left(n_{\text {sam }} / \mathbf{n}_{\text {ref }}\right)^{2} \rightarrow
$$

Where I is the measured integrated emission intensity, $\mathrm{n}$ is the refractive index of the solvent, and A is the absorbance. The subscript "ref" refers to standard with known QY and "sam" for the sample. In order to minimize reabsorption effects, absorption in the $1 \mathrm{~cm}$ fluorescence cuvette was kept below 0.10 at the excitation wavelength $(355 \mathrm{~nm})$.

2. The QY was determined by slope method using quinine sulfate as the reference:

From the integrated photoluminescence intensity and the absorbance value [several values (less than 0.1 at excitation wavelength) built the curve] of the samples with that of the references.

The equation is:

$$
Q Y_{\text {sam }}=Q Y_{\text {ref }}\left(K_{\text {sam }} / K_{\text {ref }}\right)\left(n_{\text {sam }} / n_{\text {ref }}\right)^{2} \quad \rightarrow \quad(2)
$$

Where $\mathrm{K}$ is the slope determined by the curves and $\mathrm{n}$ is the refractive index. The subscript "ref" refers to the standards and "sam" refers to the unknown samples. For these aqueous solutions, $\mathrm{n}_{\mathrm{sam}} / \mathrm{n}_{\mathrm{ref}}=1$. 


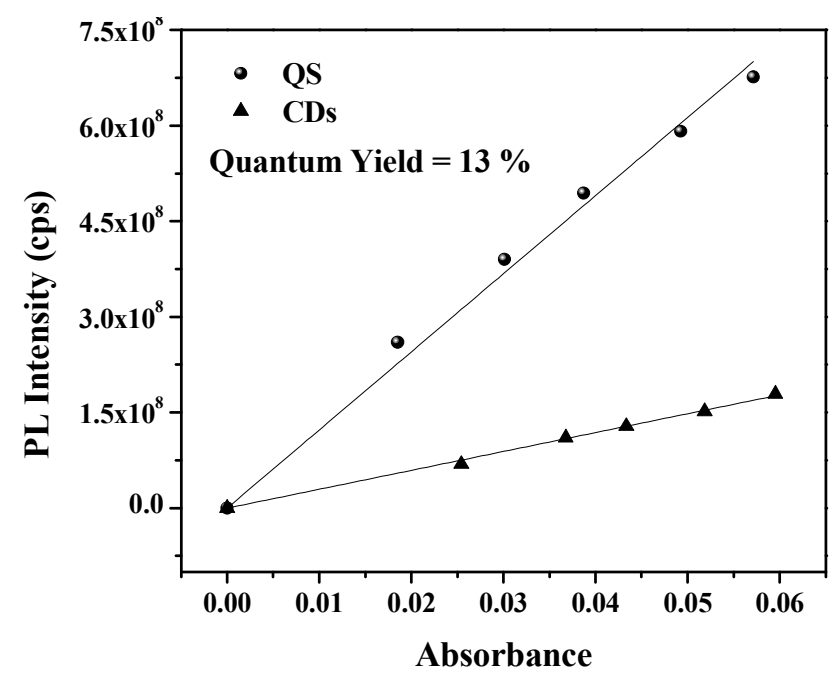

Figure S3. Slope method for QY calculation

Table S3.

for QY

using

(Graphical)

\begin{tabular}{|c|c|c|c|c|}
\hline Slope $_{\text {sam }}$ & Slope $_{\text {ref }}$ & $\left(\mathbf{n}_{\text {sam }} / \mathbf{n}_{\text {ref }}\right)^{\mathbf{2}}$ & $\mathbf{Q Y}_{\text {ref }}$ & $\mathbf{Q Y}_{\text {sam }}$ \\
\hline $2.96 \times 10^{9}$ & $1.23 \times 10^{10}$ & 1 & 0.54 & 0.13 \\
\hline \multicolumn{4}{|c|}{ Graphical QY } & $\mathbf{1 3 . 0 \%}$ \\
\hline
\end{tabular}

Slope method calculation equation 2

Table S4. Calculated QY (using equation 1)

\begin{tabular}{|c|c|c|c|c|c|c|c|}
\hline \multicolumn{2}{|c|}{ Quinine Sulphate } & \multicolumn{2}{c|}{ CDs } & \multirow{2}{*}{$\mathbf{I}_{\text {sam }} / \mathbf{I}_{\text {ref }}$} & $\mathbf{A}_{\text {ref }} / \mathbf{A}_{\text {sam }}$ & $\left(\mathbf{n}_{\text {sam }} / \mathbf{n}_{\text {ref }}\right)^{\mathbf{2}}$ & \multirow{2}{*}{$\mathbf{Q Y}$ sam $(\%)$} \\
\hline Absorbance & Emission & Absorbance & Emission & & 1 & 10.4 \\
\hline 0.019 & $2.60 \times 10^{8}$ & 0.025 & $6.90 \times 10^{7}$ & 0.264 & 0.728 & 1 & 12.5 \\
\hline 0.030 & $3.90 \times 10^{8}$ & 0.037 & $1.10 \times 10^{8}$ & 0.283 & 0.819 & 1 & 12.5 \\
\hline 0.039 & $4.94 \times 10^{8}$ & 0.043 & $1.28 \times 10^{8}$ & 0.260 & 0.893 & 1 & 13.2 \\
\hline 0.049 & $5.91 \times 10^{8}$ & 0.052 & $1.52 \times 10^{8}$ & 0.257 & 0.950 & 1 & 13.7 \\
\hline 0.057 & $6.76 \times 10^{8}$ & 0.060 & $1.79 \times 10^{8}$ & 0.265 & 0.960 & 1 & \multicolumn{6}{|c|}{ Calculated QY } & $\mathbf{1 2 . 5 0 \%}$ \\
\hline
\end{tabular}


The quantum yield obtained from graphical method and that is obtained by calculation method are matches well which shows the quality of the experiments.

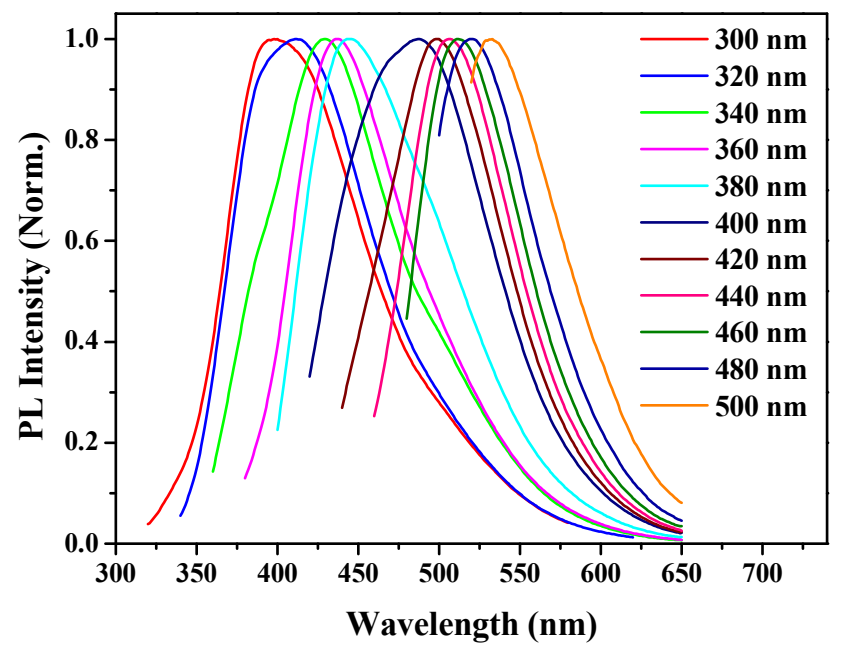

Figure S4. Normalized emission spectra at various excitation wavelengths.
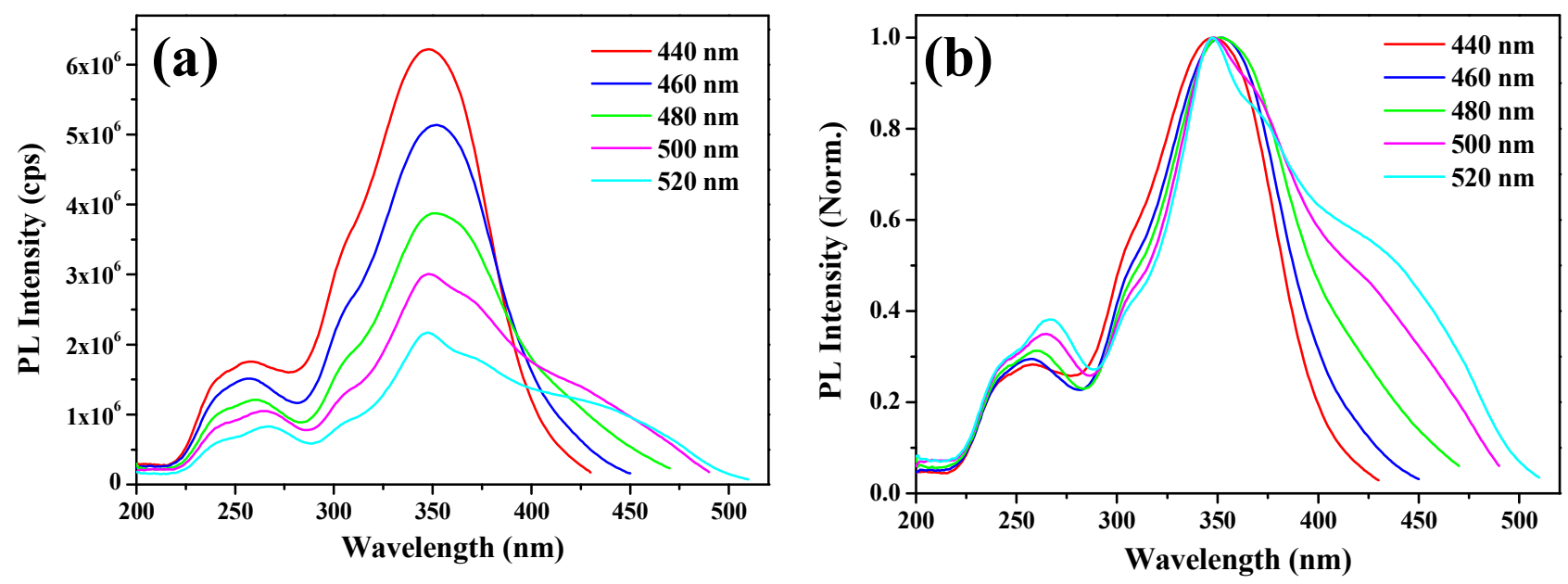

Figure S5. (a) Excitation spectra at various emission wavelengths, (b) Normalized excitation spectra at its maximum intensity 

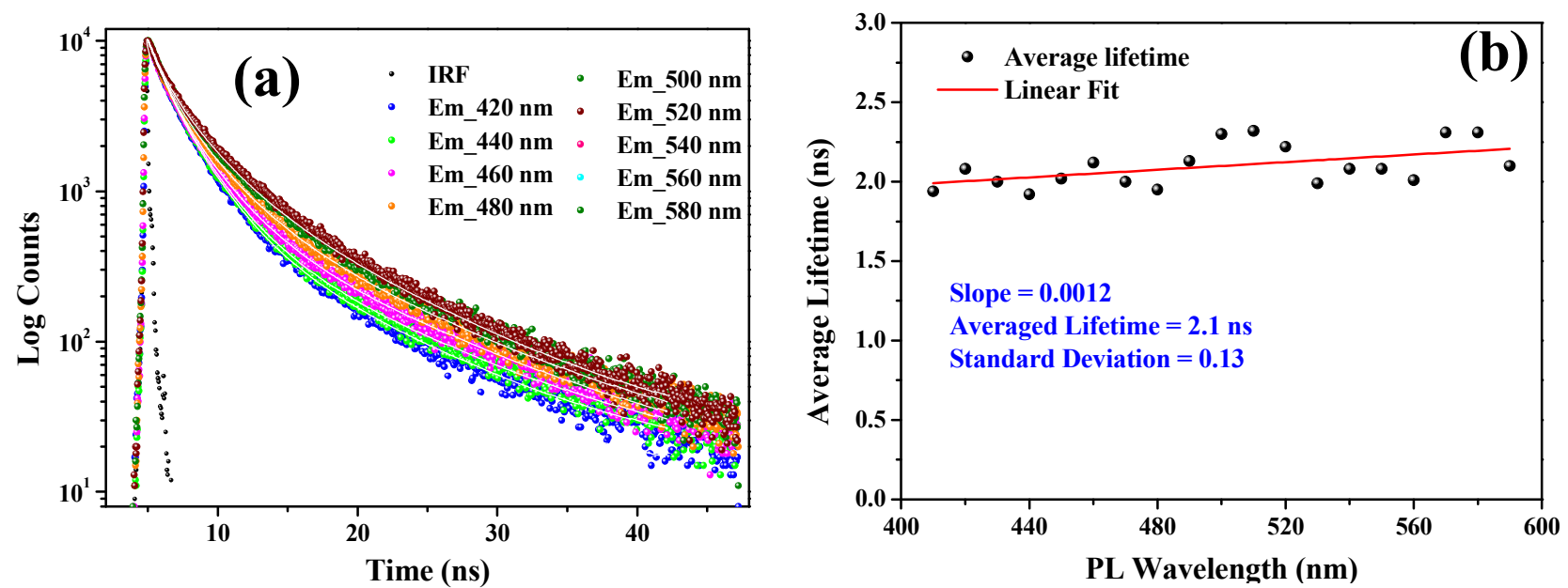

Figure S6. (a) Fluorescence lifetime decay at various emission wavelengths, (b) Linear fit of average lifetime against PL wavelength.

\section{Data Notes:}

The fluorescence decay is best fitted with a tri-exponential function and the average lifetime scattered between 1.92 ns to 2.32 ns. There is no regular trend in the average lifetime with respect to the emission wavelength and there is no much difference among the lifetimes monitored at various emission wavelengths. As an average, the average lifetime is $2.1 \mathrm{~ns}$ with a standard deviation of 0.13 . 
Table S5. Fitted parameters of fluorescence lifetime decay. $(\tau=$ lifetime, $A=$ relative amplitude $)$

\begin{tabular}{|c|c|c|c|c|c|c|c|c|c|}
\hline S. No. & $\begin{array}{c}\lambda_{\mathrm{em}} \\
(\mathrm{nm})\end{array}$ & $\begin{array}{c}\tau_{1} \\
\text { (ns) }\end{array}$ & $\begin{array}{c}\tau_{2} \\
(\mathrm{~ns})\end{array}$ & $\begin{array}{c}\tau_{3} \\
\text { (ns) }\end{array}$ & $\begin{array}{l}A_{1} \\
(\%)\end{array}$ & $\begin{array}{l}A_{2} \\
(\%)\end{array}$ & $\begin{array}{l}A_{3} \\
(\%)\end{array}$ & $\begin{array}{l}\tau_{\text {avg }} \\
\text { (ns) }\end{array}$ & Red. $\chi^{2}$ \\
\hline 1 & 410 & 0.50 & 2.08 & 7.30 & 9.14 & 60.69 & 30.16 & 1.94 & 1.10 \\
\hline 2 & 420 & 0.81 & 2.37 & 8.65 & 16.10 & 59.97 & 23.93 & 2.08 & 1.12 \\
\hline 3 & 430 & 0.95 & 2.44 & 9.21 & 24.34 & 57.09 & 18.57 & 2.00 & 1.03 \\
\hline 4 & 440 & 1.01 & 2.53 & 9.60 & 29.52 & 53.39 & 17.09 & 1.92 & 1.02 \\
\hline 5 & 450 & 1.13 & 2.70 & 9.74 & 33.87 & 48.28 & 17.85 & 2.02 & 1.11 \\
\hline 6 & 460 & 1.06 & 2.73 & 10.01 & 28.18 & 50.49 & 21.33 & 2.12 & 1.14 \\
\hline 7 & 470 & 1.05 & 2.89 & 10.00 & 33.50 & 46.35 & 20.15 & 2.00 & 1.02 \\
\hline 8 & 480 & 1.01 & 2.85 & 9.60 & 33.09 & 45.91 & 21.00 & 1.95 & 1.10 \\
\hline 9 & 490 & 1.01 & 2.94 & 9.26 & 29.11 & 45.34 & 25.55 & 2.13 & 1.03 \\
\hline 10 & 500 & 0.99 & 2.89 & 8.87 & 24.11 & 45.17 & 30.73 & 2.30 & 1.10 \\
\hline 11 & 510 & 0.98 & 3.01 & 8.78 & 24.38 & 44.02 & 31.60 & 2.32 & 1.09 \\
\hline 12 & 520 & 1.02 & 3.16 & 8.93 & 28.90 & 42.59 & 28.51 & 2.22 & 1.08 \\
\hline 13 & 530 & 0.99 & 3.32 & 9.87 & 34.69 & 42.39 & 22.91 & 1.99 & 1.23 \\
\hline 14 & 540 & 0.96 & 3.17 & 8.84 & 30.45 & 42.04 & 27.51 & 2.08 & 1.04 \\
\hline 15 & 550 & 0.96 & 3.17 & 8.85 & 30.46 & 42.05 & 27.49 & 2.08 & 1.04 \\
\hline 16 & 560 & 0.91 & 3.04 & 8.59 & 29.67 & 41.73 & 28.60 & 2.01 & 1.04 \\
\hline 17 & 570 & 0.90 & 3.07 & 8.65 & 22.54 & 44.27 & 33.19 & 2.31 & 1.04 \\
\hline
\end{tabular}




\begin{tabular}{|c|c|c|c|c|c|c|c|c|c|}
\hline 18 & 580 & 0.90 & 3.08 & 8.65 & 22.55 & 44.27 & 33.18 & 2.31 & 1.04 \\
\hline 19 & 590 & 0.95 & 3.14 & 8.80 & 30.31 & 41.98 & 27.71 & 2.10 & 1.04 \\
\hline
\end{tabular}

